\title{
Indeterminism and Free Will
}

\author{
By Prof. E. Schrödinger
}

$\mathrm{I}^{\mathrm{T}}$ has become the orthodox view of physicists to-day, that the momentary state of a physical system does not determine its movement or development or behaviour, to follow; Nature is supposed to be such that a knowledge of state, sufficiently accurate for sharp prediction of the future, is not only unobtainable but also unthinkable. All that can be predicted refers to a large number of identical experiments, and consists in a definite statistics among all the possible developments to follow. The relative margin of indeterminacy (the 'spread' of the statistics) is large for a small system, for example, for an atom ; but for large systems the margin is usually, though not necessarily, small, which makes it possible to account for the apparent determinacy of inanimate Nature.

Many eminent scientific workers, especially physicists, have tried to play with the idea that the apparent indeterminacy of animate Nature, that is, of living matter, might be connected with the theoretical indeterminacy of modern physics. What makes this play so fascinating and thrilling is evidently the hope (whether outspoken or concealed) of extracting from the new physical dogma a model of free-will, which the old one would refuse to yield. I consider this hope an illusion, for the following general reasons.

When observed objectively in other creatures, free-will actions do not call for a special 'indeterminist' explanation any more than other events. When two persons (or the same person on different occasions) react differently under apparently the same conditions, we feel compelled to account for it, whether the reaction is a passive or an active one, by a real, though unknown, difference of conditions, including, of course, character and temporary disposition on the part of the reacting persons. A poet unrolling before us the objective picture of free-will actions is just as concerned about proper causation (here called motivation) as the classical physicist was for inanimate Nature.

On the other hand, when regarded as a fact of self-observation, free-will has quite a different standing from scientific experience. The two are, as it were, in different planes, which do not intersect. Self-observed free-will I would analyse into two facts. First, indeed, a prediction, but not based on previous experience, certainly not in the way in which scientific prediction is. If I am the actor, I just know what is going to happen, and that, apart from pathological cases, with the greatest amount of certainty which is ever met with in life. The second fact is a moral one : I feel responsible for what happens.

Now, it is true that this absolute prescience is a matter only of the very last moment before or when the action sets in, which it rather accompanies than precedes. Before that there is frequently doubt and even entire ignorance ('hesitation'). This antecedent period, together with the remarkable feeling of responsibility, entails the idea of choice between different possibilities for which a clue is sought in the modern views of physics. If that were right, it would mean either one of two things. First, that the laws of Nature are after all at "my" mercy. For if my smoking or not smoking a cigarette before breakfast (a very wicked thing !) were a matter of Heisenberg's uncertainty principle, the latter would stipulate between the two events a definite statistics, say 30:70; which I could invalidate by firmness. Or, secondly, if that is denied, why on earth do $I$ feel responsible for what I do, since the frequency of my sinning is determined by Heisenberg's principle? The new physics does not shift St. Augustin's paradox by a hair's breadth.

In my opinion the whole analogy is fallacious, because the plurality of possible events, in the case of an action under free-will, is a self-deception. Think of cases such as the following: you are sitting at a formal dinner, with important persons, terribly boring. Could you, all at once, jump on the table and trample down the glasses and dishes, just for fun? Perhaps you could : maybe you feel like it : at any rate you cannot. Then, which of the virtually possible events are to be called possible under the auspices of free-will ? I would say, just the one that actually follows.

Against this view cases might be quoted where the decision is really difficult, serious, painful, bewildering, when we are down on our knees before the Almighty to forgo it. But in this $\mathrm{He}$ is inexorable! We must decide. One thing must happen, will happen, life goes on. There is no $\psi$-function in life. I have always considered this having-to-decide as a strikingly close subjective correlate to the classical, the deterministic model of Nature. It ought to be emphasized that modern physics does not compel us to abandon this correlation. The material units which determine the 
processes of life seem to be large enough forpossibly and even probably-safeguarding the essential course of these processes against any perceptible direct and immediate manifestation of the Heisenberg uncertainty.

The preceding remarks have been elicited by the first page of a highly interesting sketch by Prof. F. G. Donnan, "Integral Analysis and the Phenomena of Life" (Acta Biotheoretica, Series A, vol. 2, Pars 1, 1936 ; Leyden : E. J. Brill), though not by way of contradiction. Prof. Donnan is not concerned with the question of free-will. His idea is that an organism is to be regarded as a 'historical' system, whose reactions at a given moment are not determined alone by its surroundings and by its momentary state, but also by what has happened to that organism during a certain previous period. This is a highly attractive view, and the mathematical treatment proposed by Prof. Donnan a very suggestive one - even if one should hesitate to agree with the view (which he considers essential) that some of the historical traces are not engraved in the momentary state otherwise than by modifying its reactivity.

\section{The Institute of Experimental Psychology at Oxford}

$\mathrm{T}$ HE University of Oxford has recently enacted a statute establishing an Institute of Experimental Psychology, at which active work will be begun in the autumn. Dr. William Brown, Wilde reader in mental philosophy in the University, has been appointed its first director, with Dr. William Stephenson as his assistant. The management of the Institute is in the hands of a committee consisting of the Vice-Chancellor, a representative appointed by each of the boards of the Faculties of Medicine, Literæ Humaniores, Biological Sciences and Social Studies, together with the director.

Thus Oxford has at length officially fallen into step with the movement that has been going on for more than fifty years, the aim of which has been to free psychology from the exclusive tutelage of philosophy, and establish it as an independent, empirical and experimental science. Such freedom, however, does not imply separation, nor can the independence be more than a relative one.

In taking its place among the other natural sciences, the data of all of which provide grist for the philosophical mill, psychology will still look to philosophy, as they do, for the solution of some of the ultimate problems; though it will pursue its own proximate quests by its own empirical line of approach and the use of its own appropriate methods. Grouped together with the other sciences, again, and particularly with the biological and social sciences, there will be much overlapping and interlacing, which can only result in great mutual advantage to them all. Both these points have most wisely been taken into consideration in the constitution of the committee of management of the new Institute.

The foundation of this laboratory at Oxford is in a sense a historic event. For centuries, the University has been the home of philosophy, of which psychology has always been an integral and essential part. In the Middle Ages, Roger Bacon and Duns Scotus, no mean psychologists, stand out amongst its scholars. In the seventeenth century, the 'father' of modern psychology, John Locke, author of the famous "Essay Concerning Human Understanding", was a student of Christ Church. When the Wilde readership was founded in 1898 , a distinguished psychologist, G. F. Stout, was appointed to hold it; and he was succeeded by a no less distinguished teacher of the science than William McDougall.

An age-long tradition was there ; the conversion of rational into empirical psychology had already begun. But as yet there was no established laboratory in which systematic research could be prosecuted. One is tempted to ask why Oxford should have lagged behind when Cambridge, London, Manchester, Edinburgh forged ahead, in company with most other European and American universities, following the lead of Wundt at Leipzig. Was it opposition from the ancient vested interests of philosophy? Was it the belief that scientific psychology was a mere appendage of physiology? Did the terms of the Wilde readership, excluding experimental psychology explicitly from its purview, stand in the way? Of recent years, at any rate, it was none of these things. Before the Great War, McDougall was able for a time to direct a laboratory, housed in rooms belonging to the Department of Physiology, and having access to apparatus in use there. Solid work had already begun; and, but for the upheaval of the War years and their aftermath, it might have become permanent. But the accommodation was then urgently needed for other purposes, and funds were unavailable; so the project had to be abandoned. 